\title{
Jarvis’ Existential Learning Model: Making It Work
}

Harald Bergsteiner, Macquarie University, Australia

Gayle C. Avery, Macquarie University, Australia

\begin{abstract}
Although it is widely recognized that individuals learn in different ways, there is some disagreement on the paths learners take. Responding to Kolb's (1984) Experiential Learning Model, Jarvis proposed an Existential Learning Model to identify multiple routes that learners use. Examining Jarvis' model critically reveals some problems: the model does not reflect either its supporting text or sound modeling practices and conventions, is subject to an error in discourse, and fails to depict the specific learning routes that Jarvis' own research identified. This paper develops Jarvis' model to align it with the theory, clearly depicts learning routes, and proposes a more logical and effective model that aligns with modeling theorists' criteria.
\end{abstract}

Keywords: experiential learning, learning model, learning theory, graphical modeling

\section{INTRODUCTION}

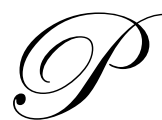

eter Jarvis' theories on how people learn, expressed in both words and graphical models, have been very influential. He has shown that human learning follows many different paths. However, the quality of modeling does not match the quality of his written contribution, and this has been the subject of criticism (e.g. Smith, 1996). Given the widespread attention to Jarvis' Existential Learning Model, it is timely to examine it in graphical modeling terms. Does it communicate Jarvis' learning theory accurately and effectively, and can the model be improved for practitioners and researchers by applying accepted modeling principles?

For learning theory, critically examining Jarvis' model has two benefits. First, it highlights the power of a potentially excellent model showing multiple ways of learning. Second, it demonstrates the importance of applying modeling principles in a rigorous manner to support or express theory. Applying accepted graphic modeling conventions and Britt's (1997) simplification and sufficiency tests to Jarvis' model, show that it is not effective as a communication tool because the theory as espoused in words is not reflected in the model. To help communicate the importance of Jarvis' theory better, this paper subjects his existential model to scrutiny, simplifies the form of the model, and "complexifies" the content. We first identify and address weaknesses in the model, and then suggest modifications to the model to increase its efficacy, including making the model more consistent with Jarvis' written text.

\section{MODELS AS COMMUNICATION TOOLS}

There is a growing recognition in many disciplines that graphics and models can communicate patterns and relationships that might be difficult to communicate with text (Britt, 1997; Vessey, 1991; Ware, 2000). In the natural sciences and technology, the ability to visualize obscure or shrouded processes has led to break-through innovations and insights. This is particularly evident in chemistry, molecular modeling, astrophysics, and semiconductor design (Gordin and Pea, 1995; Van Dam, 1992). Crosby (1997) attributes the explosive development of modern science to visualization and measurement, yet the social sciences lag behind other sciences in effective use of graphics. Professional disciplines such as engineering and architecture depend heavily on graphics and models. In the construction industry, sketches, diagrams, drawings, graphics, charts, maps, pictures (e.g. photos of models), and images (e.g. perspective drawings) are a primary means of communication. Some are subject to strict conventions for showing cross-sections of materials such as timber, concrete, bricks, and metal on construction drawings, or for showing plans, sections, and elevations (Walker and Chaplin, 1997). In other words, somewhat similar to written 
language, there is a graphic syntax that those professionals are expected to learn and use to facilitate ease of, and accuracy in, communication.

Unfortunately, adherence to graphic conventions is not widespread in the social sciences. We know, for example, that in the field of management visual literacy is low (Knight, 1999; Murranka and Lynch, 1999; Wardrope and Bayless, 1999), resulting in oversimplified models (Mintzberg and Van der Heyden, 1999); misleading graphics (Tufte, 1983); and graphics that lack coherence, consistency, and rigor. In fact, several authors argue that the lack of good modeling in management is hampering the development of theory in that field (Branch, 1999; Leipzig and More, 1982; Markham, 1998; Mintzberg and Van der Heyden, 1999). Similar trends appear in other social science disciplines (Smith, Best and Stubbs, 2003).

This malaise has its roots in two factors. First, the teaching of graphic and modeling skills appears to be limited to practitioners and academics of disciplines related to the physical sciences (Walker and Chaplin, 1997). Second, while editors of journals and publishers of books get involved in the minutiae of sentence construction, the management literature abounds with graphics that lack differentiation and integration, are poorly structured and designed, do not reflect and respect prior theory, lack logic and coherence, and/or mislead (Beattie and Jones, 1992; Bergsteiner and Avery, 2003; Trumbo, 1997; Tufte, 1983). With this background, it is not surprising that many published graphical models contain flaws, including Jarvis' learning model.

\section{PROBLEMS WITH JARVIS' MODEL}

Jarvis' model was to some extent a response to Kolb’s (1984) much earlier model. Jarvis considered Kolb's model overly simplistic in that it did not show the many different ways in which people could respond to potential learning situations. Jarvis therefore conducted empirical studies with different adult groups and asked them to explore Kolb's model, bearing in mind their own learning experiences. This led him to develop a model that has become increasingly more complex over time. The latest version, reviewed here (see Figure 1), alludes to eight routes of learning that are, however, not made graphically explicit. The routes are difficult to identify and distinguish, especially for an audience likely to be low in graphical literacy. For, while the model shows links (lines connecting pairs of boxes), it does not show learning routes (lines connecting a specific set of boxes). The routes can only be ascertained by reference to the text, with a certain amount of toing and froing between the model and the text. This defeats the purpose of the graphical model, graphics being particularly effective at showing complex relationships in a parsimonious way (Britt, 1997).

Figure 1: Jarvis' (2004) Model of Learning Processes

Source: Jarvis (2004) - Linkages not referred to in Jarvis' text are shown dotted

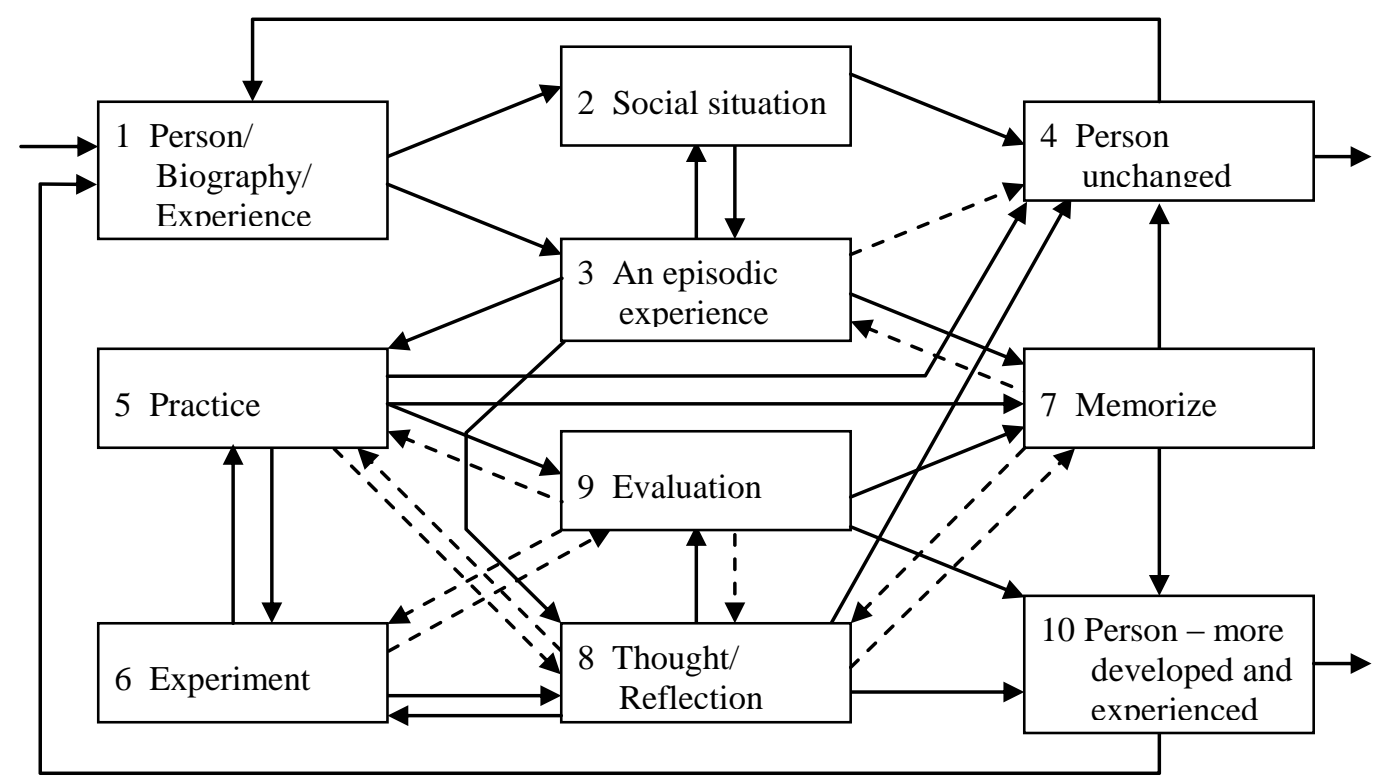


Furthermore, some linkages implied as logically possible in the model are not discussed in Jarvis' accompanying text. Thus, developing the model would have benefited from a more systematic alignment of its content with the written text, as discussed next. Examining the model closely also reveals a discourse problem.

\section{Inconsistency In Text And Graphic}

Supporting Jarvis' graphical model is a list of learning and non-learning routes or patterns. Therefore, whereas Kolb essentially proposed one cyclical route (concrete experience > observations and reflections > formulation of abstract concepts and generalization > testing implications of concepts on new situations >), Jarvis identified many alternative routes that involve different components of his model. In Table 1, we list the various learning routes or learning patterns identified by Jarvis, together with the names he gave those routes/patterns. The table also draws out Jarvis' distinctions between reflective and non-reflective learning, as well as incidental and purposeful learning.

Reading Figure 1 in conjunction with the text (as summarized in Table 1) reveals a number of incongruities between the two. The model shows various bi-directional links that are not referred to in the text (Boxes 5 and 8 , Boxes 7 and 8, Boxes 6 and 9). The model also shows three bi-directional links that are described as one-way in the text (Boxes 3 and 7, Boxes 8 and 9, Boxes 5 and 9). For example, the model shows a link from Box 3 to Box 7; however, the various routes discussed by Jarvis make no mention of a route that involves such a link. He refers only to a link from Box 7 to Box 3. Perhaps these graphic links allude to other theoretically possible routes that Jarvis hypothesizes in his book, but that do not specifically derive from his research, and hence are not discussed. If these links do occur, the question arises as to how they relate to the other boxes. After all, one presumes that similar to the other routes they form part of some pattern.

Table 1: Jarvis' (2004) types of learning and non-learning

Suggested changes shown in brackets

\begin{tabular}{|c|c|}
\hline Learning type & Route on model \\
\hline \multicolumn{2}{|l|}{ Non-learning } \\
\hline i taken for granted/presumption & $1>2>4$ (delete from learning model) \\
\hline \multicolumn{2}{|l|}{ ii non-consideration } \\
\hline \multicolumn{2}{|l|}{ iii rejection } \\
\hline \multicolumn{2}{|l|}{ Non-reflective learning } \\
\hline \multicolumn{2}{|l|}{ Incidental non-reflective learning } \\
\hline Learning about self through non-consideration and rejection & $(1>2>3)>8>10$ \\
\hline Preconscious knowledge learning & $(1>2>3)>7>4$ (change 4 to 10$)$ \\
\hline Preconscious skills learning & $(1>2>3)>5>4($ change 4 to 10$)$ \\
\hline \multicolumn{2}{|l|}{ Conscious non-reflective learning } \\
\hline Basic skills learning & $(1>2>3)>5>7>10$ \\
\hline Memorization & $(1>2>3)>7>10$ \\
\hline \multicolumn{2}{|l|}{ Reflective learning } \\
\hline Cognitive learning & $(1>2>3)>5>6>8>9>7>10$ \\
\hline Practice learning & $(1>2>3)>8>6>5>9>7>10$ \\
\hline Contemplation (when a result of social experience) & $(1>2>3)>8>9>7>10$ \\
\hline (when a result of private experience) & $1>3>8>9>7>10$ (delete) \\
\hline
\end{tabular}

\section{Problem Of Discourse}

Jarvis (2004) justifiably criticizes definitions of learning that propose that new cognitive knowledge has only been acquired when it results in behavioral change. The important point that Jarvis makes is that there is a potential for change, a potential that arises precisely because of the acquisition of new learning. The fact that people choose to or are prevented from enacting the new learning does not mean that they have not learned, nor does it negate the learning. 
In seeming contradiction to his own stand, Jarvis then identifies a learner who has acquired preconscious knowledge or skills as an unchanged person (Box 4). But a person who does not translate preconscious learning into overt behavior is no more to be equated with an unchanged person than a person who does not change behavior even though there has been cognitive learning. In both cases, new knowledge has been acquired, which has not been made use of. In other words, using Jarvis' very own argument, preconscious learning of whatever variety (knowledge, skills, attitudes, beliefs, values, emotions and the senses) opens up opportunities for persons to engage (or not) in new behavior. That is to say, when a person has learned, a person has changed. Whether behavior has changed is another matter. Even people with no memory for daily life, anterograde amnesiacs, can learn (Milner, 2005). The most famous case is H.M., who had forgotten all previous learning sessions, and hence was unaware that he was learning, but was still able to gradually improve on a motor skill.

\section{SIMPLIFYING AND COMPLEXIFYING THE CONTENT OF JARVIS' MODEL}

In the following, we simultaneously simplify certain theoretical aspects of Jarvis' model, while extending its scope in other respects. As a follow-on step, we simplify the graphics.

The finding that a person changes as a result of preconscious learning suggests that on Jarvis' model, preconscious knowledge learning should not follow the route $1>2>3>7>4$, which signifies an absence of learning and therefore an unchanged person, but the route $1>2>3>7>10$. (Note that this follows the same route as for "conscious non-reflective memorization"). Similarly, preconscious skills learning should not follow the route $1>2>3>5>4$, but the route $1>2>3>5>10$. Examination of the sequences in Table 1 shows that when the sequences for preconscious knowledge and skills learning are rerouted to finish at Box 10, no remaining links terminate at Box 4. In other words, Box 4 essentially has relevancy only in relation to non-learning. Box 4 can therefore be removed from the model, since the focus of the model is learning and not non-learning. Before embarking on actual modifications to Jarvis' model, we address another opportunity for simultaneously simplifying and complexifying the model.

Table 1 shows that all of the routes identified by Jarvis start with the Boxes 1, 2 and 3, except for the nonlearning route $1>2>4$, and a particular variant of the contemplation route $1>3>8>9>7>10$. The latter variant is said to arise when individuals are totally lost in their own thoughts as a result of a private, that is non-social, experience. By differentiating between contemplation as a response to a social rather than a private situation, Jarvis may unnecessarily constrain his model in two ways. First, in addition to social and private "lost-in-thought" situations, environmental, physical, psychological, physiological, and other situations give rise to episodic experiences. Jarvis (2004: 109) recognizes this when he talks about, for example, "the smell that we associate with certain places" clearly an allusion to an environmental situation. These are situations that the model in its current form does not appear to recognize.

Second, all Jarvis' learning routes initially follow the pattern $1>2>3$, except for contemplation as a result of a private experience, which starts with $1>3$. Replacing "social situation" simply with situation would embrace private as well as social, environmental, physical, psychological, physiological, and other situations. This wider interpretation of situation removes the need for a separate route $1>3>8>9>7>10$, which then allows contemplation to be represented with just the one sequence $1>2>3>8>9>7>10$. This coincidentally means that all sequences now start with $1>2>3$. That being the case, Britt's (1997) simplification test can be applied resulting in the three boxes being replaced by one box. This change does not diminish the explanatory power of the model. On the contrary, it extends the scope of the model by allowing for environmental, physical, psychological, physiological, and other situations to trigger a learning episode.

\section{SIMPLIFYING THE GRAPHICS}

A question posed by Smith (1996) in response to an earlier version of Jarvis' model is equally applicable here, namely whether the components of the model could be grouped together in a different and more compact way. This is highly desirable since the model in its current form is of limited utility. 
Smith (1996) criticized Jarvis' model for being overly complex and difficult to interpret. As discussed above, this is a consequence of an overly complex graphic that obscures the essential message of the model, namely the learning routes. Good graphic modeling requires the removal of graphic elements that merely create clutter without adding meaning (Britt, 1997; Tufte, 1983; Ware, 2000). This suggests replacing pairs of counter-directional arrows in Figure 1 with single bi-directional arrows. This action reflects modelers' credo that models are most effective when they display complexity in content but are parsimonious in the means of expression (Mintzberg and Van der Heyden, 1999; Tufte, 1983; Ware, 2000).

\section{RECASTING JARVIS' LEARNING MODEL}

Implementing the various changes recommended above yields the Partially Simplified Existential Learning Model (Figure 2a). In their aggregate, the changes simultaneously achieve simplification (combining the learning modes $1>2>3$ in one box, removing Box 4, simplifying the arrows), and complexification (expanding the scope of "situation" to encompass more variance in context, widening the definition of learning).

Figure 2: Partially Simplified Experiential (a) and Regrouped Existential Learning (b) Models (based on Jarvis (2004))

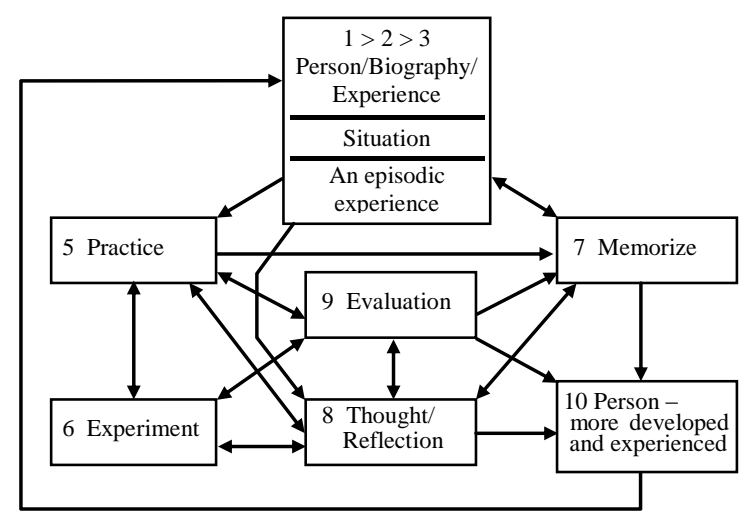

(a)

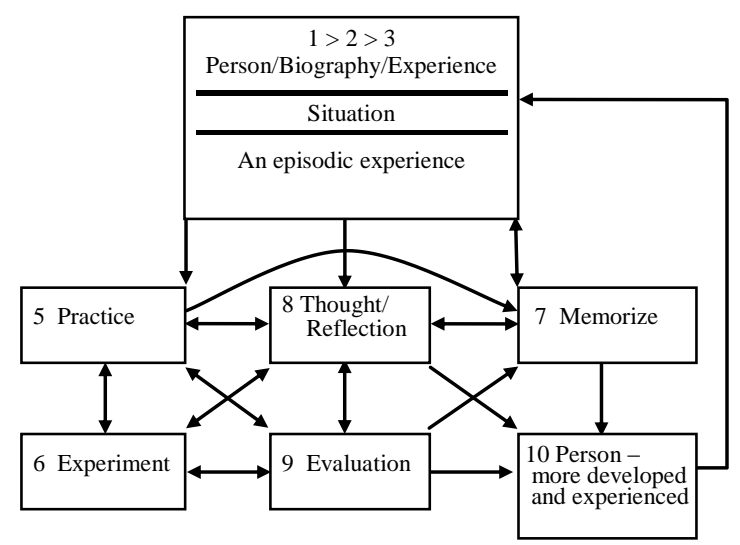

(b)

\section{Minimizing Crossovers}

However, this model is still somewhat obscure, and requires greater clarity. Constructing effective models is, among other things, a topological challenge. To make models as readable as possible, crossovers of lines should be minimized. Modeling research also shows that symmetry is a powerful organizing principle (Ware, 2000), and that "the more constrained a notation or architecture, the greater the explanatory power of resulting models" (Pylyshyn, 1980: 126). Figure 2b shows a regrouped version of Jarvis' model. By reversing the positions of Boxes 8 and 9, as shown in Figure 2b, the number of crossovers is reduced from five to three. Coincidentally a more coherent pattern of relationships evolves. Note that all links shown in Figure 2a have been retained in Figure 2b, including those that Jarvis does not discuss in his book.

\section{REVEALING JARVIS' LEARNING ROUTES}

Figure $2 \mathrm{~b}$ depicts a much simplified and more readable version of the Jarvis model. However, this model still does not depict the learning routes identified by Jarvis. Having to identify the routes by constant reference back to the text is tedious and lacking in clarity, and does not fully exploit the power of graphics. Therefore, further modification is necessary to clearly highlight Jarvis' learning routes. This requires a somewhat more dramatic change to the model, necessitating several further iterations before arriving at the final model. Indeed, for extra 
clarity two models were generated, one for reflective and one for non-reflective learning. Figure 3a shows nonreflective learning processes, while Figure $3 \mathrm{~b}$ depicts reflective learning processes. A careful comparison of these models with Table 1 shows that all the specific linkages identified and discussed by Jarvis are still there; they have simply been recast into a different form. However, the linkages shown dotted in Figure 1 have been eliminated because they play no role in any of the specific routes identified and discussed by Jarvis.

Figure 3: Non-Reflective (a) and Reflective Learning(b) Models (based on Jarvis' (2004) learning routes)

(a) Non-Reflective Learning Model

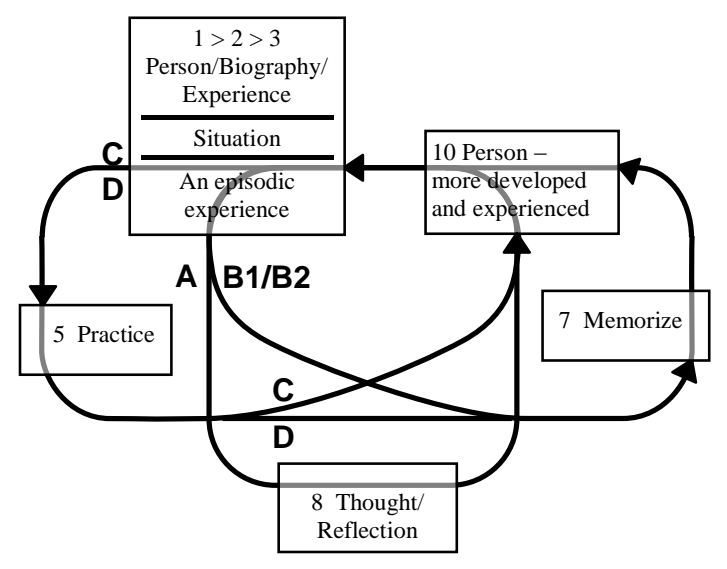

A: learning about self

B1: pre-conscious knowledge learning

B2: conscious memorization

C: pre-conscious skills learning

D: conscious basic skills learning (b) Reflective Learning Model

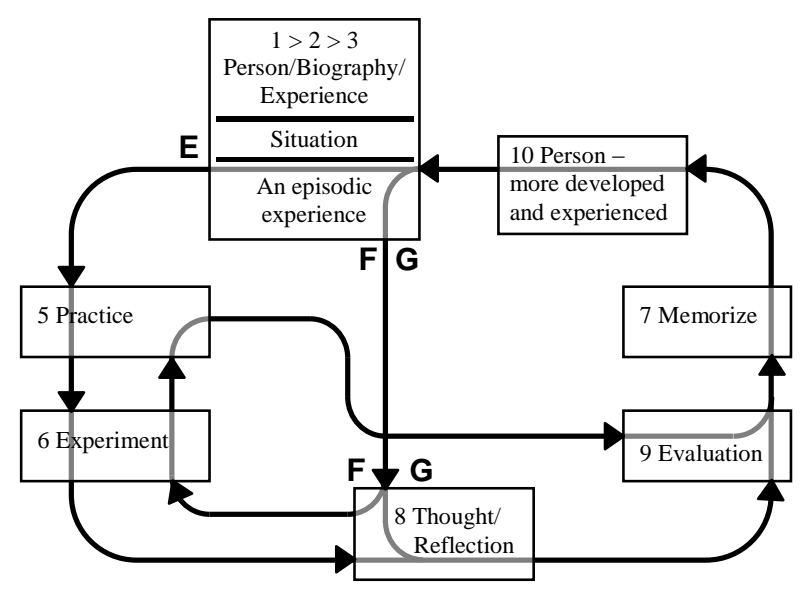

E: Cognitive learning
F: Practice learning
G: Contemplation

The resultant model highlights a contradiction in Jarvis' theory. Whereas Jarvis' text describes learning about the self as non-reflective in nature, the model shows that this learning pattern, in fact, passes through Box 8, which denotes "thought/reflection". This contradiction was not immediately apparent from the original model, given that model's opaqueness. Therefore, this is another example of how clarity in modeling can aid the development and refinement of theory.

The Non-Reflective Learning Model now shows the five non-reflective patterns of learning in an easily discernable manner (A, B1, B2, C, D). Each route starting at Box 1>2>3 is clearly distinguishable from the other routes. Yet at the same time, commonalities in routes become apparent. For example, both routes $\mathrm{C}$ and $\mathrm{D}$ involve practice, but route $\mathrm{C}$ goes straight to Box 10 (person more developed and experienced), and route D goes to Box 10 via Box 7 (memorize). This model also highlights the circular nature of learning much better than the original. The Reflective Learning Model (Figure 3b) is more complex than Figure 3a because it involves another two learning facets (experiment and evaluation). In addition, some quite circuitous learning patterns are discernable in Figure $3 \mathrm{~b}$. Even so, three reflective learning routes can be followed with ease, helped among other things by the fact that there is only one crossover.

\section{Combining Routes}

For readers able to interpret a higher degree of graphic complexity, the two models in Figures $3 a$ and $3 b$ can be combined (Figure 4), thus allowing all routes to be compared on the one model. However, simply superimposing Figure $3 \mathrm{a}$ on Figure $3 \mathrm{~b}$ is not a desirable graphical option because it results in too many crossovers. 
Figure 4 contains a completely different arrangement again, which results in only one crossover at Box 8 . Figure 4 is now much clearer than the original model (Figure 1) since it allows the routes to be traced without needing to refer to the text.

Figure 4: Composite Existential Learning Model

(based on Jarvis' (2004) learning routes)

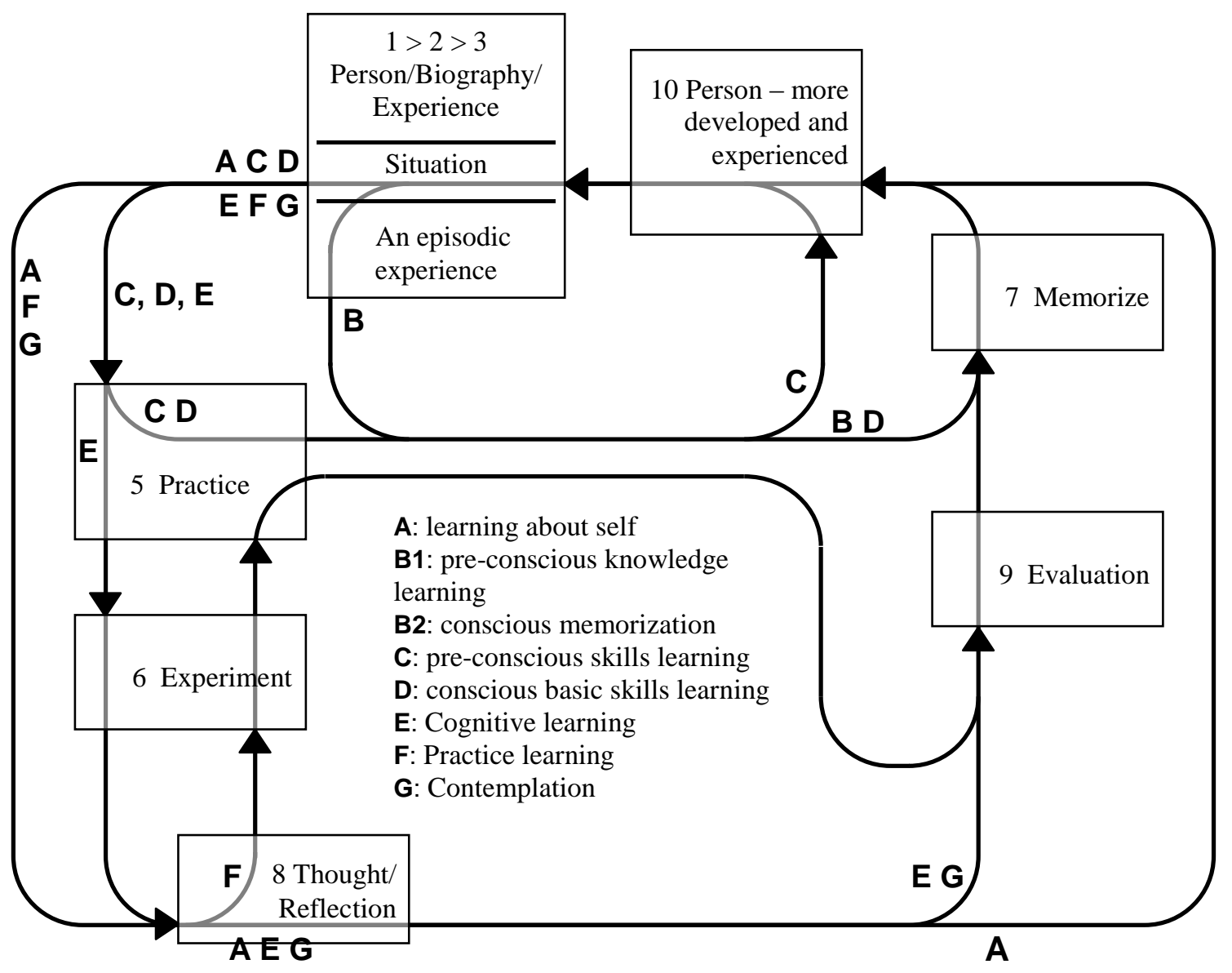

If future research shows that people use other learning routes, then these can either be added to the composite model in Figure 4 or to one of the two separate models in Figures $3 \mathrm{a}$ and $3 \mathrm{~b}$ above. Alternatively, it may be necessary to generate a further model, using the same basic constellation of boxes. Theory building and modeling are iterative processes, so as new evidence comes to light, models and theories may need adjustment.

\section{CONCLUSION}

Jarvis (2004) proposed a learning model to address deficiencies that he perceived in Kolb's (1984) learning model. However, Jarvis' model is itself problematic in that it is overly complex in some respects, while not communicating the raison d'etrê of his model, namely the routes of learning, effectively. With the exception of drawing attention to a problem of discourse, our intention was not to question the validity of Jarvis' research, but to show that ineffective graphic modeling has unnecessarily obfuscated the important information Jarvis was trying to convey. The revised model better conveys what we hope was Jarvis' intended message, and should provide a better basis for testing his research findings, and hence for developing the model further. Recasting Jarvis' model to create a simpler basic structure, whilst adding complexity in content, has also highlighted the important contribution good 
modeling can make to communicating complex processes effectively. Omissions, unnecessary concepts, and contradictions in Jarvis' theory have been highlighted during this process. These examples demonstrate how clarity and rigor in modeling can aid the development and refinement of theory.

\section{AUTHOR INFORMATION}

Harald Bergsteiner is Adjunct Professor in Management and Director of International Relations at the Institute for Sustainable Leadership, Macquarie Graduate School of Management, Sydney, and co-director of his own consulting organization. Originally trained as an architect and urban planner, he has a doctorate in management from Macquarie University, and has worked in Australia, the USA, and Europe. His major research interests are sustainable leadership, accountability, learning theory, and modeling management processes.

Gayle C. Avery is Professor in Management specializing in leadership at the Macquarie Graduate School of Management, Sydney. She is Director of the Institute for Sustainable Leadership, and has extensive experience working both inside and outside academia in Australia, Germany, and the USA. Her main research and teaching interests are sustainable leadership and management development. She is consultant to major international corporations, mainly in the Asia-Pacific region.

\section{REFERENCES}

1. Beattie, V. and Jones, M. J. (1992). The use and abuse of graphs in annual reports: Theoretical framework and empirical study. Accounting and Business Research, 22(88), 291-303.

2. Bergsteiner, H. and Avery, G. C. (2003). Making graphic management models smarter. International Business \& Economics Research Journal, 2(12), 47-58.

3. Branch, G. (1999). Spiraling towards the 'perfect' product. Machine Design, 71(17), 14.

4. Britt, D. W. (1997). A conceptual introduction to modeling: Qualitative and quantitative perspectives. Mahwah, NJ: Lawrence Erlbaum.

5. Crosby, A. W. (1997). The measure of reality: Quantification and western society, 1250-1600. Cambridge, England: Cambridge University Press.

6. Gordin, D. N., and Pea, D. P. (1995). Prospects for scientific visualization as an educational technology. Journal of the Learning Sciences, 4(3), 249-279.

7. Jarvis, P. (2004). Adult education and lifelong learning. Theory and practice. (3rd edn), London: RoutledgeFalmer.

8. Knight, M. (1999). Writing and other communication standards in undergraduate business education: A study of current program requirements, practices, and trends. Business Communication Quarterly, 62(1), $10-28$.

9. Kolb, D. A. (1984). Experiential learning: Experience as the source of learning and development. Englewood Cliffs, NJ: Prentice-Hall.

10. Leipzig, J. S., and More, E. (1982). Organizational communication: A review and analysis of three current approaches to the field. The Journal of Business Communication, 19(4), 77-92.

11. Markham, S. E. (1998). The scientific visualization of organizations: A rationale for a new approach to organizational modelling. Decision Sciences, 29(1), 1-23.

12. Milner, B. (2005). The medial temporal-lobe amnesic syndrome. Psychiatric Clinics of North America, 28(3), 599-611.

13. Mintzberg, H., and Van der Heyden, L. (1999). Organigraphs: Drawing how companies really work. Harvard Business Review, 77(5), 87-94.

14. Murranka, P. A., and Lynch, D. (1999). Developing a competency-based fundamentals of management communication course. Business Communication Quarterly, 62(3), 9-23.

15. Pylyshyn, Z. W. (1980). Computation and cognition: Issues in the foundations of cognitive science. The Behavioral and Brain Sciences, 3, 11-133.

16. Smith, L.D., Best, L.A., and Stubbs, D.A. (2003). Bolstering science and practice through graphism. American Psychologist, 58(10), 818-819.

17. Smith, M. K. (2001). David A. Kolb on experiential learning. The encyclopedia of informal education, http://www.infed.org/b-explrn.htm, accessed 26.10.2007. 
18. Trumbo, J. (1997). The process of critique in visual communication. Journalism and Mass Communication Educator, 52(2), 15-23.

19. Tufte, E. R. (1983). The visual display of quantitative information. Cheshire, CT: Graphics Press.

20. Van Dam, L. (1992). A picture is worth 1,000 numbers. Technology Review, 95(4), 34.

21. Vessey, I. (1991). Cognitive fit: A theory-based analysis of the graphs versus tables literature. Decision Sciences, 22, 219-240.

22. Walker, J. A., and Chaplin, S. (1997). Visual culture. Manchester: Manchester University Press.

23. Wardrope, W. J., and Bayless, M. L. (1999). Content of the business communication course: An analysis of coverage. Business Communication Quarterly, 62(4), 33-40.

24. Ware, C. (2000). Information visualization: Perception for design. San Francisco, CA: Morgan Kaufmann.

\section{$\underline{\text { NOTES }}$}


NOTES 